\title{
Om museernas historiebruk och förändringsarbetets utmaningar
}

Rita Paqualén

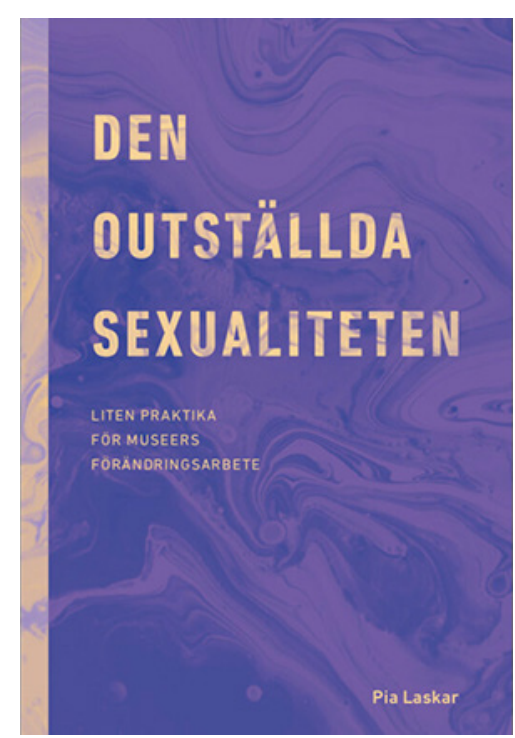

Pia Laskar. 2019. Den outställda sexualiteten. Liten praktika för museernas förändringsarbete. National Historical Museums, FoU Rapport nr 18, 125 sidor.

Under de senaste drygt tio åren har jag med stort intresse följt med den museipolitiska diskussionen i Sverige i frågor gällande demokrati, normer och representation. Det svenska museifältet har på många sätt varit en föregångare i Norden och har under 2000-talet genom ett flertal olika projekt och utställningar uppmärksammat och sökt korrigera en snedvriden representation på museer. Under de senaste åren har dessvärre de queera och normkritiska perspektiven inom kulturarvssektorn i Sverige mött på stort motstånd och misstänkliggjorts.
Ett uttryck för detta är den så kallade "kulturarvsdebatten" " som pågick under åren 2016-2018. Den kan ses som en backlash-reaktion mot de forskningstraditioner och metoder som problematiserar normer, ideal, marginaliseringar och privilegier på kulturarvsfältet.

Under 2010-talets första hälft granskade och utvecklade Statens historiska museer sin verksamhet ur ett feministiskt, normkritiskt och queert perspektiv genom två större forskningsbaserade projekt (JÄMUS 2011-2012 och Polysemantiskt digitalt museisamlande 2012-2014). Speciellt viktiga för utvecklandet av det svenska museifältet i frågor gällande HBTIQ har varit det nätbaserade aktivistmuseet The Unstraight Museum och under senare år, projektet Unstraight Research i museer (2016-2018) som två av Statens historiska museer - Livrustkammaren och Historiska museet - deltog i.

Syftet med projektet Unstraight Research i museer var att "hitta metoder för att problematisera förgivettagna föreställningar om sexualitet och kön och för att granska idéer som slentrianmässigt upprepar dagens identiteter

1 För den som är intresserad av Kulturarvsdebatten rekommenderas länklistan som Riksantikvarieämbetet sammanställt över debatten: http:/www.genusarv. se/kulturarvsdebatten-2017-raas-lanklista/ (länken kopierad 10.7.2020) 
och förståelser av det förflutna” (11). Idéhistorikern och docenten Pia Laskar var anställd som forskare i projektet och hennes bok Den outställda sexualiteten. Liten praktika för museernas förändringsarbete (2019) är ett av resultaten av projektet. Boken baserar sig på det samarbete och de diskussioner med museianställda samt workshoppar och dialoger som arrangerades inom projektet samt på de evenemang som arrangerades inom ramen för det av projektet etablerade nätverket Kulturarv och den tvärvetenskapliga genusforskningen.

I det inledande kapitlet "Varför en liten praktika för museernas förändringsarbete?" diskuterar Pia Laskar museernas roll som kunskapsproducerande och normerande institutioner. Museerna äri dag viktiga platser för lärande och den information som de producerar uppfattas ofta som sann. Genom museernas samlingar, beskrivningar, rekryteringar samt urvals- och kurateringsprocesser skapar de en bild av samhället, av nuet och dået, och av vem som ingår i den föreställda gemenskapen. För att motarbeta en missvisande representation av samhället och en exkluderande museipraktik krävs ett medvetande om vilket slags historiebruk och vilka slags normer som styrt det egna museets verksamhet.

Den outställda sexualiteten är Pia Laskars bidrag till detta förändringsarbete. Bokens syfte är "att bistå med erfarenheter och kunskap för att undvika att (åter)skapa missvisande och partiska utställningar och berättelser på museer" såsom exempelvis "museers tidigare marginalisering av sexualiteter och kön, speciellt sådana [...] som inte svarat mot samhällets normer" (11). Boken är en praktisk handledning i hur museerna kan genomföra ett förändringsarbete som inte enbart förstärker status quo och de normer som museerna historiskt byggt på, utan som svarar både mot dagens komplexa behov och framtidens frågor.

Den outställda sexualiteten består av fem kapitel. Varje kapitel innehåller en reflekterande del och en del med konkreta tips för förändring och tips för vidare läsning. I fokus för bokens första kapitel står museernas historiebruk samt det historiemedvetande som de genom sitt historiebruk och sina samlingar ger upphov till. Genom att granska museernas historiebruk kan vi, menar Laskar, "få syn på vilka ideal eller normer som museerna eller samhället de representerat främjat över tid" (20). Genom att synliggöra museets historiebruk blir vi också medvetna om de perspektiv och grupper som blivit exkluderade genom att ensidiga normativa ideal skapats.

När Laskar talar om att problematisera museers historiebruk gällande kön och sexualitet avser hon inte ett identitetspolitiskt projekt - "istället för att överföra en nutida förståelse av sexuella identiteter" borde museer våga sig på "att beskriva hur den nutida uppfattningen uppstått" (22). Genom att studera museernas tidigare historiebruk kan man synliggöra de normer, uteslutningsprocesser och maktperspektiv som skapat dagens förståelser av sexuella ideal. Intressant i detta sammanhang är även att undersöka hur nationens identitetsbyggande projekt har reglerat sexualitet och tillåtna könsuttryck.

\section{Modeller för förändring}

I bokens andra kapitel "Modeller för inkludering" beskrivs fyra olika modeller för hur museerna genom sina utställningar kan jobba mer inkluderande till exempel gällande sexuella och könsminoriteter. Modellerna, som inspirerats av skolvärlden och pedagogen Kevin Kumashiros pedagogik för att inkludera tidigare marginaliserade grupper, kallar Laskar för: 1) utställningar för de marginaliserade, 2) utställningar om de marginaliserade, 3) utställningar som är kritiska till privilegiering och marginalisering, och 4) utställningar som förändrar/rubbar verksamheten och besökaren. Laskar påpekar att innan någon av modellerna tas i bruk borde museerna först kartlägga hur de marginaliserade framställts eller exkluderats i det egna museet.

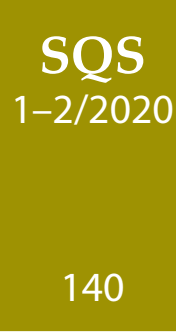

Queer Blick

Recension

Recension 
Modellerna handlar å ena sidan om verksamheter som uppmärksammar och välkomnar de tidigare marginaliserade grupperna genom separata och tillfälliga utställningar eller specialvisningar, och som förmedlar kunskap till alla besökare om de marginaliserade gruppernas situation och historia, å andra sidan om praktiker som fokuserar de privilegierade och de normer, processer, slentrianmässiga språkbruk eller upprepningar som bidragit till exkludering och marginalisering i samhället och i dess följd även på museerna. I de två sistnämnda modellerna diskuteras museernas eget arbete, en möjlig omlärningsprocess och ett synliggörande av olika historiebruk på museerna.

I sin presentation av modellerna analyserar Laskar även de risker användandet av modellerna kan medföra. En adderingsstrategi kan till exempel reproducera en stereotyp bild av sexuella och könsminoriteter, osynliggöra intersektionella variationer inom gruppen och lämna den normativa historieskrivningen oproblematiserad. I synliggörandet av sexuella och könsminoriteternas historia finns det även en risk att man även applicerar dagens syn på kön och sexualitet eller samlevnadsformer på historiskt material. Riskerna med de två sistnämnda modellerna handlar om den utmaning som ett ifrågasättande av etablerade strukturer, normer och historiebruk kan medföra internt och externt.

\section{Förändringsarbetets utmaningar}

Att förändra sätten att närma sig historien, att problematisera normativa historiebruk och att leda sin personal in i ett förändringsarbete gällande arbetsrutiner inom museet och dess samlingspolitiska program kräver mod och framför allt mycket förberedelse. Även om många museer är villiga att lyfta fram tidigare marginaliserade grupper genom olika additiva metoder eller specialvisningar, är steget mot ett ifrågasättande av museets tidigare historiebruk mycket svårare att ta, eftersom det kräver ett ibland tungt omlärningsarbete. Det innebär ofta även ett synliggörande av de privilegier man själv åtnjuter och av de maktrelationer och exkluderande praktiker som format museerna historiskt. I bokens tre sista kapitel "Utmaningar, möjligheter - samarbeten över professionsgränser", "Nästa steg i förändringsarbetet" och "Att synliggöra museernas inställning" fokuserar Pia Laskar därför på hur museerna kan samarbeta med aktörer utanför museet i sitt förändringsarbete, hur förändringsarbetet kan förankras inom organisationen och hur museer genom krisberedskap kan förbereda sig på reaktioner som förändringsprocessen eventuellt innebär.

Den outställda sexualiteten är ett välkommet redskap för museer som vill förändra sin verksamhet för att bära sitt ansvar som dokumenterande och kunskapsförmedlande institution och för att svara mot de behov som dagens komplexa värld ställer. Liksom Therese Quinn i boken School: Questions about Museums, Culture, and Justice to Explore in Your Classroom (2020), som också recenseras i detta nummer, fokuserar även Laskar på museet som institution och på behovet av en strukturomvandling. För att museerna ska vara samhällsrelevanta och inkluderande krävs mer än en adderande jämställdhetsstrategi. Museerna måste också bli medvetna om och synliggöra sitt historiebruk, hur normer skapas samt hur olika kategorier och identiteter har uppstått i ett samspel mellan makt och motstånd.

Styrkan i Pia Laskars bok är just det analytiska och kritiska greppet, ett förhållningssätt som nästan förutsätter en forskningsmässig distans till det vardagliga arbetet inom museerna. Just genom detta professionella utanförskap möjliggörs ett tänkande utanför boxen, något som vi alla oberoende av verksamhetsområde - skulle vara betjänta av. Den outställda sexualiteten kan således även fungera som inspiration för förändringsarbetet inom andra sektorer på konst- och kulturfältet eller exempelvis inom utbildningssektorn. 


\section{Referenser}

\section{Litteratur}

Fernståhl, Lotta. 2011. Genusperspektiv i museer. En omvärldsbevakning. Stockholm: Statens historiska museum. http://www.sverigesmuseer.se/wp/wpcontent/uploads/2011/12/J\%C3\%84MUS_omv\%C3\%A4rld.pdf (länken kopierad 10.7.2020).

Quinn, Therese. 2020. School: Questions about Museums, Culture, and Justice to Explore in Your Classroom. New York \& London: Teachers College Press.

Uppdrag jämställda museer. 2013. Rapport om regeringsuppdraget att ta fram underlag och utveckla metoder för en mer jämställd representation i samlingar och utställningar. Statens historiska museer FoU Rapport 10. Stockholm: Statens historiska museum. https://shm.se/wp-content/ uploads/2016/05/Jamusrapport.pdf (länken kopierad 10.7.2020).

\section{Nätsidor}

Kort info om projektet Unstraight Research i museer (2016-2018) och länk till Pia Laskars bok Den outställda sexualiteten. https://shm.se/unstraightresearch-pa-museum/ (länken kopierad 10.7.2020).

Nätsidan för nätverket Kulturarv och den tvärvetenskapliga genusforskningen http://www.genusarv.se/ (länken kopierad 10.7.2020). 